\title{
An intervention to empower and engage the self-help groups for menstrual hygiene in Karnataka, India
}

\section{Reshmi RS $^{1 *}$, Manoj Kumar Gupta ${ }^{2}$, Dhirendra Kumar ${ }^{3}$, Fehmida Visengrawala ${ }^{4}$}

\author{
${ }^{1}$ Assistant Professor, Institute of Health Management Research (IIHMR), Bangalore, Karnataka, India \\ ${ }^{2}$ Assistant Professor and Dean Research Coordinator, Institute of Health Management Research (IIHMR), Bangalore, \\ Karnataka, India \\ ${ }^{3}$ Professor, Institute of Health Management Research (IIHMR), Jaipur, Rajasthan, India \\ ${ }^{4}$ Visiting Professor, Institute of Health Management Research (IIHMR), Bangalore, Karnataka, India
}

Received: 19 September 2014

Accepted: 10 October 2014

\section{*Correspondence:}

Dr. Reshmi RS,

E-mail: srreshmi@gmail.com, reshmir@iihmr.org

Copyright: (C) the author(s), publisher and licensee Medip Academy. This is an open-access article distributed under the terms of the Creative Commons Attribution Non-Commercial License, which permits unrestricted non-commercial use, distribution, and reproduction in any medium, provided the original work is properly cited.

\begin{abstract}
Background: This paper was a part of 'Multi-centric action research demonstration study' with the aim to sensitize, mobilize and engage women regarding reproductive health through empowerment and engagement of the Self Help Groups (SHGs) women. The paper focuses on the effect of intervention on menstrual hygiene and health of women in Kolar district of Karnataka.

Methods: As an intervention, a total of fifteen workshops, targeting 75 SHGs in each, were conducted using predeveloped IEC material in intervention taluk. A total of 400 households (200 from each intervention and control sites) of SHG women were interviewed for baseline and endline each

Results: The intervention was found effective in the form of a significant improvement in the level of awareness regarding use of Napkins/sanitary pads and its disposal. Apart from this, the level of awareness regarding menstrual discharge abnormalities was also significantly improved. However, the intervention was insignificant in molding area specific misconceptions and practices during menstruation such as access to worship, entry into kitchen, mingle with people etc.

Conclusions: The results of the present study clearly indicate the feasibility, efficacy and significant impact of health education interventions in improving the level of knowledge, attitude and practices of women regarding menstrual hygiene and point out that cost-effective strategy through information, education, and behavior change are needed in this regard.
\end{abstract}

\section{INTRODUCTION}

Menstruation is the cyclical shedding of the inner lining of the uterus, the endometrium, under the control of hormones of the hypothalamopituitary axis. It is an important process which results in the sexual and reproductive capacity of woman. Though menstruation is a natural process, it is linked with several misconceptions and practices in India due to different rituals in the communities, which sometimes result into adverse health outcomes. ${ }^{1}$ Those misconceptions and taboos compel women to react negatively at menarche and maintain discomfort in discussing menstrual health issues. ${ }^{2}$ Studies have shown that restrictions to perform religious rituals during menstruation are the most common restriction observed by women during their menstruation. ${ }^{1,3}$ One common way, that even sanitary-product advertisements avoid mentioning menstruation is by pouring a blue liquid on the sanitary item to demonstrate its absorptiveness. ${ }^{4}$ This shows the stigma surrounding the blood associated with menstruation. 
Menstrual hygiene deals with a woman's special health care needs and requirements during her monthly menstrual cycles. ${ }^{5}$ Poor menstrual hygiene in developing countries has been an insufficiently acknowledged problem. ${ }^{6}$ The lack of attention to this issue is striking. Approximately half of the world population knows from their own experience how important good menstrual hygiene is to be able to function optimally during the menstruation period. ${ }^{7}$ The knowledge regarding menstrual hygiene and safe menstrual practices are important as the vulnerability of having Reproductive Tract Infections (RTIs) is much less among women having better knowledge about menstrual hygiene and practices ${ }^{3}$. Studies have shown that most of the women do not use sanitary pads during their menstruation. ${ }^{8,9}$

Menstrual hygiene and social taboos are issues needs to be addressed at all levels. The issues of poor menstrual hygiene management have been ignored or misunderstood by the society as well as the policy makers. $^{5}$ It is important to empower women about menstrual health and hygiene as it is significantly associated with the reproductive health of a woman. The issues of menstrual hygiene discussed through health education are an essential resource for improving menstrual hygiene in women especially in less developed countries. $^{8,10}$ Thus, it is essential to design a mechanism to address and for the access of healthy menstrual practices. $^{3,8}$ There is a need to educate and empower women about safe and hygienic practices during menstruation and bring them out of traditional beliefs, taboos and misconceptions. In this context, the present study was planned with the notion that development and use of Information Education Communication (IEC) material along with active participation by the community ensures delivery of appropriate information and knowledge to people which in turn empowers them to make informed decisions about their health. Realizing it, this research work with a specially designed preventive intervention was formulated to study the impact on knowledge, attitude and practices regarding menstrual hygiene among Self Help Groups (SHGs) women.

\section{Objective}

The objective of this paper is to understand the effect of intervention on change in knowledge, attitude and practice associated with menstruation among women in Kolar district, Karnataka.

\section{METHODS}

Data used for this paper has been taken from the original study which was a 'Multi-centric action research demonstration study' to sensitize, mobilize and engage women through the SHGs, to take care of their reproductive health, including cervical cancer, and act as change agents for other women in the community. The study was conducted for a period of one and half year (from May 2012 to October 2013). Initial three months was preparatory phase which was utilized for extensive literature search, designing and finalization of interview schedules, baseline data collection in the form of Household Surveys (HHS) and Focus Group Discussions (FGDs) and development of IEC material. Next one year was intervention phase in which series of workshops were conducted with the help of pre-developed IEC material to increase the awareness of SHGs members. Last three months were utilized for end line survey by means of HHS and FGDs, data analysis and write up work.

Overall this multi-centric study was spread over five districts in 3 states namely Karnataka, Rajasthan and Chhattisgarh. The Kolar district in Karnataka was the primary intervention site. From Kolar district an intervention taluk (Bangarpet) was selected from eleven taluks of Kolar District by simple random sampling. To establish an adequate counterfactual, a nearby taluk (Malur) with similar geographical, climatic, development and health indicators was selected as control by adopting purposive sampling. In both these taluks, quantitative evaluation using household surveys and qualitative evaluation with FGDs were done at baseline and end line. As an intervention, a total of fifteen workshops, each consisting three days, targeting 75 SHGS in each were conducted in Bangarpet taluk. Overall the sensitization was done with the help of local NGOs working in intervention sites. In Dharwad, Koppala, Jaipur and Raipur districts only qualitative evaluation using FGDs were done, and only two workshops, each consisting three days, were conducted. The present article is based on quantitative data analysis of intervention, Kolar district of Karnataka.

\section{Sample size}

As per the literature search and by assuming the minimum prevalence $(50 \%)$ for awareness and practices regarding proper menstrual hygiene among SHG women and considering $10 \%$ permissible level of error in the estimated prevalence, the sample size was calculated: $z^{2}$

$$
n=\frac{z^{2} p q}{L^{2}} \quad n=\frac{1.96 \times 1.96 \times 50 \times 50}{(5)^{2}}=384.16
$$

The total sample size was round up and fixed to 400. A total of 400 households (200 from Bangarpet and 200 from Malur) of SHG women were targeted for interview for baseline and endline each. However, the total number of households covered during baseline survey was 397 (200 in Malur and 197 in Bangarapet) and end line survey was 401 (197 in Malur and 204 in Bangarapet).

\section{Selection of Households}

There are three Community Mobilization Research Centres (CMRCs) in Bangarpet taluk (Kamsamudra, Topanahalli and Buddikotte) and two CMRCs in Malur taluk (Thoralakki and Dinnahalli). From each CMRC, six 
villages were selected by simple random sampling method. Thus total 30 villages were selected for the study. In the selected villages total enumeration of SHG women was done to prepare a sampling frame. The required study subjects for each village was fixed adopting Probability Proportion to Size (PPS) sampling technique. In order to get required study subjects, simple random sampling was done.

Data thus generated was analyzed using SPSS v16.0. Appropriate tables and graphs were generated and chi square test was applied to draw inferences. The statistical significance was computed using the chi-square test for proportions and a $\mathrm{p}$ value of $<0.05$ was taken as significant and $<0.01$ was considered as highly significant.

\section{RESULTS}

Table 1 presents the socio-economic and demographic profile of the respondents in Malur and Bangarapet taluks in Kolar district during baseline and end line surveys. It is evident from the table that the mean age of the respondents during baseline survey and end line survey was 31.4 years $(\mathrm{SD}=6.7)$ and 32.7 years $(\mathrm{SD}=7.3)$, respectively. There was no significant variation in the mean age of the respondents in Malur and Bangarapet taluks. More than 95 percent of the respondents in both the taluks were currently married. More than 60 percent of the respondents in Malur and around three fourth of the respondents in Bangarapet taluk were belonging to nuclear family. A vast majority of the respondents were Hindus. With regard to caste of the respondents, more than 35 percent of the respondents belong to scheduled caste or scheduled tribes and more than one fourth belong to Other Backward Castes (OBC) in both the taluks. More than 90 percent of the respondents have a ration card. It is to be noted here that majority of the respondents in both Malur and Bangarapet taluks belong to either Below Poverty Line (BPL) or extremely BPL category. Thus, socio-economic and demographic milieu were almost same for both intervention and control taluks.

Table 1: Socio-economic and demographic profile of the respondents.

\begin{tabular}{|c|c|c|c|c|}
\hline \multirow{3}{*}{ Characteristics } & \multicolumn{2}{|l|}{ Baseline } & \multicolumn{2}{|l|}{ End line } \\
\hline & Malur & Bangarapet & Malur & Bangarapet \\
\hline & $\%(\mathrm{~N})$ & $\%(\mathrm{~N})$ & $\%(\mathrm{~N})$ & $\%(N)$ \\
\hline \multicolumn{5}{|l|}{ Age } \\
\hline Less than 25 years & 14.5 & 13.7 & 12.8 & 9.8 \\
\hline $25-29$ years & 29.0 & 23.4 & 25.6 & 24.5 \\
\hline $30-34$ years & 18.5 & 22.3 & 14.9 & 17.6 \\
\hline $35-39$ years & 21.5 & 26.9 & 24.6 & 27.9 \\
\hline 40 years and above & 16.5 & 13.7 & 22.1 & 20.1 \\
\hline Mean age & $\begin{array}{l}31.5 \\
\mathrm{SD}=6.9\end{array}$ & $\begin{array}{l}31.4 \\
\mathrm{SD}=6.5\end{array}$ & $\begin{array}{l}32.8 \\
\mathrm{SD}=7.5\end{array}$ & $\begin{array}{l}32.6 \\
\mathrm{SD}=7.1\end{array}$ \\
\hline \multicolumn{5}{|l|}{ Marital status } \\
\hline Currently married & 99.0 & 95.9 & 97.0 & 94.1 \\
\hline Others & 1.0 & 4.1 & 3.0 & 5.9 \\
\hline \multicolumn{5}{|l|}{ Type of family } \\
\hline Nuclear family & 68.1 & 74.1 & 61.1 & 73.4 \\
\hline Joint/third generation & 31.9 & 25.9 & 39 & 26.6 \\
\hline \multicolumn{5}{|l|}{ Religion } \\
\hline Hindu & 95.5 & 94.4 & 96.4 & 97.5 \\
\hline Others & 4.5 & 5.6 & 3.6 & 2.5 \\
\hline \multicolumn{5}{|l|}{ Caste } \\
\hline $\mathrm{SC} / \mathrm{ST}$ & 36.9 & 35.4 & 39.6 & 36.3 \\
\hline $\mathrm{OBC}$ & 25.8 & 28.7 & 26.9 & 31.9 \\
\hline Others & 37.4 & 35.9 & 33.5 & 31.9 \\
\hline \multicolumn{5}{|l|}{ Has ration card } \\
\hline Yes & 94.0 & 92.9 & 93.9 & 97.1 \\
\hline No & 6.0 & 7.1 & 6.1 & 2.5 \\
\hline \multicolumn{5}{|l|}{ Economic status* } \\
\hline BPL/extreme BPL & 87.2 & 97.3 & 98.9 & 99.5 \\
\hline APL & 10.6 & 2.2 & 1.1 & 0.0 \\
\hline Don't know & 2.1 & 0.5 & 0.0 & 0.5 \\
\hline Total & $100(200)$ & 100 (197) & 100 (197) & $100(204)$ \\
\hline
\end{tabular}


The distribution of the respondents based on their knowledge, attitude and practice towards menstrual hygiene are shown in Table 2 . At baseline, nearly three fourth of the respondents were aware about the use of napkins and sanitary pads in both intervention and control taluks. However, during end line survey, the proportion of respondents who were aware about the use of sanitary pads was significantly $(\mathrm{P}<0.05)$ higher in Bangarapet as compared to Malur. With regard to the material used during menstruation, only near about one fifth of the respondents were using sanitary pads during baseline survey in both Malur and Bangarapet taluks and remaining four fifth of the SHGs women were using cloth most of the times during menstruation. At endline survey, a considerable increment was observed in the proportion of women who had shifted to sanitary pads from cloth in both the taluks. But, the shift was more prominent in Bengarapet taluk (79.4\%) as compared to Malur taluk (43.1\%). The major source of sanitary napkins was from retail shops in both the taluks (not shown in table).

Table 2: Distribution of the respondents based on their knowledge, attitude and practice towards menstrual hygiene.

\begin{tabular}{|c|c|c|c|c|c|c|}
\hline \multirow{3}{*}{ Characteristics } & \multicolumn{2}{|l|}{ Baseline } & \multirow{3}{*}{ P value } & \multicolumn{2}{|l|}{ End line } & \multirow{3}{*}{ P value } \\
\hline & Malur & Bangarapet & & Malur & Bangarapet & \\
\hline & $\%(\mathrm{~N})$ & $\%(\mathrm{~N})$ & & $\%(\mathbf{N})$ & $\%(\mathrm{~N})$ & \\
\hline \multicolumn{7}{|c|}{ Aware about use of napkins/sanitary pads } \\
\hline Yes & 74.5 & 77.2 & \multirow{2}{*}{0.308} & 83.8 & 99.0 & \multirow{2}{*}{$<0.05$} \\
\hline No & 25.5 & 22.8 & & 16.2 & 1.0 & \\
\hline \multicolumn{7}{|c|}{ Material use most of the times during menstruation } \\
\hline Cloth & 76.5 & 75.1 & \multirow{3}{*}{0.468} & 56.3 & 19.6 & \multirow{3}{*}{$<0.05$} \\
\hline Sanitary pads & 22.0 & 22.8 & & 43.1 & 79.4 & \\
\hline Others & 1.5 & 2.0 & & 0.5 & 1.0 & \\
\hline \multicolumn{7}{|c|}{ Encouragement for using sanitary napkin pads } \\
\hline Cheap/affordable & 31.0 & 31.0 & \multirow{4}{*}{0.537} & 68.6 & 29.7 & \multirow{4}{*}{$<0.05$} \\
\hline Good quality & 42.0 & 42.6 & & 28.8 & 69.2 & \\
\hline Easily available & 24.5 & 21.3 & & 2.5 & 1.1 & \\
\hline User friendly & 2.5 & 5.1 & & 0 & 0 & \\
\hline \multicolumn{7}{|c|}{ Change of napkins or cloths at least once a day } \\
\hline Yes & 92.0 & 91.4 & \multirow{2}{*}{0.482} & 98.5 & 99.0 & \multirow{2}{*}{0.479} \\
\hline No & 8.0 & 8.6 & & 1.5 & 1.0 & \\
\hline \multicolumn{7}{|c|}{ Cloth or napkin disposal } \\
\hline Burn it & 36.5 & 46.7 & \multirow{2}{*}{0.025} & 57.9 & 90.2 & \multirow{2}{*}{$<0.05$} \\
\hline Others & 63.5 & 53.3 & & 42.1 & 9.8 & \\
\hline Total (No.) & $100(200)$ & $100(197)$ & & $100(197)$ & $100(204)$ & \\
\hline
\end{tabular}

The respondents were asked to report the factors which encourage the use of sanitary napkins. The most reported reasons were good quality as well as affordability. Nearly 40 percent of the women in both Malur and Bangarapet during baseline survey reported that they prefer sanitary pads because of its good quality. However, during end line survey the major reason for using sanitary pads among women in Malur taluk was affordability (68.6\%) while good quality $(69.2 \%)$ was found as major encouragement factor for using sanitary pads in Bangarapet taluk.

Majority $(>90 \%)$ of women in the study area were following good practice of changing napkins during periods at least once in a day. During base line survey, the ways of disposing napkins were burying, burning, throwing in garbage and other methods. After intervention, majority $(90.2 \%)$ of $\mathrm{SHG}$ women in
Bangarapet had adopted burning as the method of disposal for used napkins.

Women were asked regarding their access for worship, entry into kitchen; mingle with people and about being considered impure or dirty at the time of menstruation. Table 3 depicts the distribution of SHGs women according to misconceptions and practices associated with menstruation. At the time of baseline survey, 40 percent of the women in Malur taluk and 64 percent of the women in Bangarapet taluk reported that they were not allowed to worship during menstruation. A considerable increment was found in the proportion of women who were allowed to worship in both Malur and Bangarapet at the time of endline survey. Nevertheless, the difference was more apparent in Bangarapet. There was only slight change in proportions of respondents with regard to misconception related to menstruation in terms of entry into kitchen, to mingle with people and being 
considered impure or dirty at the time of menstruation in both intervention and control taluks. This indicates that area specific misconception and practices for menstruation and a strong web of social taboos in Indian society which calls for a long term planned intervention to break the misconceptions and malpractices and to make significant changes in this regard.

Table 3: Distribution of women according to misconceptions and practices associated with menstruation.

\begin{tabular}{|c|c|c|c|c|c|c|}
\hline \multirow{3}{*}{ Characteristics } & \multicolumn{2}{|l|}{ Baseline } & \multirow{3}{*}{ P value } & \multicolumn{2}{|l|}{ End line } & \multirow{3}{*}{ P value } \\
\hline & Malur & Bangarapet & & Malur & Bangarapet & \\
\hline & $\%(\mathrm{~N})$ & $\%(\mathrm{~N})$ & & $\%(\mathrm{~N})$ & $\%(\mathrm{~N})$ & \\
\hline \multicolumn{7}{|c|}{ Allowed to worship } \\
\hline Yes & 60.1 & 36.1 & \multirow{2}{*}{$<0.05$} & 93.4 & 90.2 & 0.162 \\
\hline No & 39.9 & 63.9 & & 6.6 & 9.8 & \\
\hline \multicolumn{7}{|c|}{ Allowed to mingle with anyone } \\
\hline Yes & 58.6 & 79.4 & \multirow{2}{*}{$<0.05$} & 46.2 & 73.0 & $<0.05$ \\
\hline No & 41.4 & 20.6 & & 53.8 & 27.0 & \\
\hline \multicolumn{7}{|c|}{ Considered impure } \\
\hline Yes & 69.7 & 19.1 & \multirow{2}{*}{$<0.05$} & 54.8 & 7.8 & $<0.05$ \\
\hline No & 30.3 & 80.9 & & 45.2 & 92.2 & \\
\hline \multicolumn{7}{|c|}{ Allowed to enter kitchen } \\
\hline Yes & 78.8 & 47.4 & \multirow{3}{*}{$<0.05$} & 84.8 & 57.8 & $<0.05$ \\
\hline No & 21.2 & 52.4 & & 15.2 & 42.2 & \\
\hline Total & $100(198)^{*}$ & $100(194)^{*}$ & & $100(197)$ & $100(204)$ & \\
\hline
\end{tabular}

Note: there were 2 missing cases in Malur and 3 missing cases in Bangarapet taluk

It is evident from Table 4 that the levels of awareness regarding menstrual discharge abnormalities such as foul smelling discharge, presence of clots in menstrual blood and scanty amount of blood in menstruation were not at all satisfactory during the baseline survey. Only $25.9 \%$ and $21.3 \%$ respondents in Bangarapet and Malur taluks, respectively were aware that a foul smell in menstrual discharge is abnormal. With the help of designed intervention, a highly significant $(\mathrm{P}<0.01)$ improvement in awareness level was observed in intervention taluk as compared to control taluk. Presence of clots in menstrual blood was being considered abnormal by only $42.4 \%$ and $31.0 \%$ women in Bangarapet and Malur taluks, respectively. A considerable improvement in the level of awareness in this regard was observed in intervention taluk during end line survey. Nearly half of the respondents in both the taluks accepted that there is some abnormality in menstruation if discharge is scanty in amount. This figure of accurate knowledge was increased to $78 \%$ for Bangarapet during endline survey and was significantly $(\mathrm{P}<0.01)$ higher than control taluk $(55.6 \%)$.

Table 4: Distribution of the respondents by awareness regarding the menstrual discharge abnormality.

\begin{tabular}{|c|c|c|c|c|c|c|}
\hline \multirow{3}{*}{ Characteristics } & \multicolumn{2}{|l|}{ Baseline } & \multirow{3}{*}{ P value } & \multicolumn{2}{|l|}{ End line } & \multirow{3}{*}{$P$ value } \\
\hline & Malur & Bangarapet & & Malur & Bangarapet & \\
\hline & $\%(N)$ & $\%(N)$ & & $\%(N)$ & $\%(N)$ & \\
\hline When it is foul smelling & 21.3 & 25.9 & 0.195 & 28.6 & 74.0 & $<0.01$ \\
\hline When there are clots & 31.0 & 42.4 & 0.021 & 37.0 & 89.2 & $<0.01$ \\
\hline When it is scanty & 49.4 & 50.6 & 0.456 & 55.6 & 77.9 & $<0.01$ \\
\hline Total & $100(168)^{*}$ & $100(158)^{*}$ & & $100(189)^{*}$ & $100(204)^{*}$ & \\
\hline
\end{tabular}

Note: Remaining cases were not aware about the menstrual discharge abnormality

Near about one third of the respondents in both Malur and Bangarapet during baseline survey reported that they had some kind of health problems during menstruation. However, during end line survey, those reported problems were reduced to only $9.8 \%$ for Bangarapet and
$15.3 \%$ for Malur. The prominent reduction in menstrual health problem in intervention taluk may be because of the increased health seeking behavior of the women, as one of the components of intervention was to improve the health seeking behavior of the community (Figure 1). 


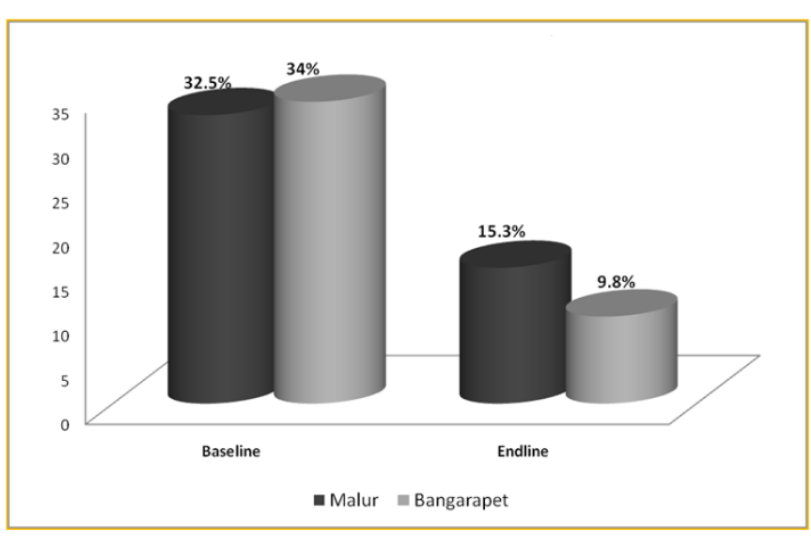

Figure 1: Proportion of women who had any health problem during menstruation.

\section{DISCUSSION}

Having a safe and cultural environment to manage menstruation hygienically and with dignity is one of the important rights for every woman. Nevertheless, this is an under-addressed issue which may be because menstrual hygiene management is often neglected in general health agendas. ${ }^{11}$

Even after existing social marketing scheme of sanitary napkins by government and a lot of media advertisements, merely three fourth of the respondents were found aware about the use of napkins and sanitary pads in both intervention and control taluks. This awareness level could be improved significantly through the planned intervention. Type of menstrual absorbent used constitutes a foremost component of menstrual hygiene as unsanitary material may harbor infectious agents. It was seen in present study that only near about one fifth of the respondents were using sanitary pads most of the times during menstruation. This figure is in accordance with the findings of a study conducted by Rani (2014) in Chittoor District of Andra Pradesh, ${ }^{12}$ but considerably higher than the findings of various others studies $^{9,13}$ and Hindustan Latex Family Planning Promotion Trust (HLFPPT), India. ${ }^{14}$ Similar kind of poor management of menstruation has been observed by many studies. ${ }^{10,15-18}$ A study by Nemade et al. (2009) in Navi Mumbai $^{17}$ had shown that the most common type of cloths used was cotton followed by terracotta and nylon. However, present study shows its limitation in assessing the type of cloth used during menstruation. At endline survey, a considerable increment was observed in the proportion of women who had shifted to sanitary pads from cloth. Similar kind of significant impact of health educational intervention had been observed by Arora et al. (2013) in Haryana, ${ }^{10}$ Nemade et al. (2009) in Navi Mumbai ${ }^{17}$ and Dongre et al. (2007) in Maharashtra. ${ }^{19}$

It is found in the present study that the various factors were affecting the selection and use of sanitary napkins. Among those factors quantity as well as affordability of sanitary pads was playing a vital role in the selection process in the study area, which is in accordance with the findings of Karthikeyan et al. (2013). ${ }^{20}$ Similar to the findings of the study by Rani (2014), ${ }^{12}$ majority of women in the present study were following good practice of changing napkins during periods at least once in a day. During base line survey, the ways of disposing napkins were burying, burning, throwing in garbage and other methods. These findings are supported by findings of Nemade et al. (2009) $)^{17}$ and Rani (2014). ${ }^{12}$ After intervention, majority of women in Bangarapet had adopted burning as the method of disposal of used napkins.

Knowledge increment is a prominent element in health education programs. It is a necessary factor in changing health behaviors which is the ultimate goal for any health education programs. But an increase in knowledge does not always cause behavior to change. ${ }^{21,22}$ The present study was in agreement with Seidman $(1990)^{23}$ who stated that women's knowledge seemed to affect their practices during menstruation. In the existing Indian cultural milieu, the society is interwoven into a set of traditions, myths and misconceptions especially about menstruation and related issues. Area specific misconceptions and practices for menstruation were being followed in the study areas also, like access for worship, entry into kitchen; mingle with people and about being considered impure or dirty at the time of menstruation. These findings are witnessed by many studies. $1,10,12,24$ There was not much improvement in the attitude of women in the post-test regarding those social restrictions and taboos, which is in accordance with the findings of Arora et al. (2013), ${ }^{10}$ Dhingra et al. (2009), ${ }^{15}$ Udgiri et al. (2010) ${ }^{25}$ and Nemade et al. (2009). ${ }^{17}$

A considerable improvement in the level of awareness regarding menstrual discharge abnormalities such as foul smelling discharge, presence of clots in menstrual blood and scanty amount of blood in menstruation was observed in intervention taluk during end line survey. Poor awareness of menstrual abnormalities has been noted by various other studies. ${ }^{26,27}$ In the present study near about one third of the respondents in study area reported that they have some kind of health problems during menstruation. Omidvar et al. $(2011)^{28}$ had studied dysmenorrhea and menstrual irregularity and common symptoms of dysmenorrhea like tiredness, anger, and backache among young females in Mysore district of Karnataka. Present study has its limitation in assessing those symptoms.

\section{CONCLUSION}

The present study has revealed unsatisfactory level of knowledge, unhealthy menstrual practices and various area specific misconceptions among SHGs women regarding menstruation. The results clearly indicate the feasibility, efficacy and significant impact of health education interventions in improving the level of knowledge, attitude and practices of women regarding menstrual hygiene. In view of the above results it is 
recommended that we need to have appropriate costeffective strategies to address on issues related to menstrual hygiene through information, education, and behavior change.

\section{ACKNOWLEDGMENTS}

The authors of the study are grateful to Indian Council of Medical Research (ICMR) for providing funding and all the SHGs women who participated in this study.

Funding: The study was funded by Indian Council of Medical Research (ICMR)

Conflict of interest: None declared

Ethical approval: The study was approved by the ethics committee of Karnataka Institute of Medical Sciences (KIMS), Hubli, Karnataka

\section{REFERENCES}

1. Dasgupta A, Sarkar M. Menstrual hygiene: how hygienic is adolescent girl? Indian J Community Med. 2008;33(2):77-80.

2. Jackson TE. Women wearing white: discourses of menstruation and the experience of menarche. Feminism Psychol. 2013;23(3):379-98.

3. Verma P, Ahmad S, Srivastava RK. Knowledge and Practices about menstrual hygiene among higher secondary school girls. Indian J Community Health. 2013;25(3):265-71.

4. Williams LR. Beliefs and attitudes of young girls regarding menstruation. In: Sharon Golub, eds. Menarche. 1st ed. Lexington, MA: Lexington; 1983.

5. Juyal R, Kandpal SD, Semwal J. Social aspects of menstruation related practices in adolescent girls of district Dehradun. Indian J Community Health. 2013;25(3):213-6.

6. Reem Bassiouny El-Lassy, Abeer Abd El-Aziz Madian. Impact of health educational program on menstrual beliefs and practices of adolescent Egyptian girls at secondary technical nursing school. Life Sci J. 2013;10(2):335-45.

7. Kibret M. Knowledge, attitude and practice on reproductive health among high school students in Bahir. Dar, Ethiopia. Afr J Reprod Health. 2003;7:39-45.

8. Shah SP, Nair R, Shah PP, Modi DK, Desai SA, Desai L. Improving quality of life with new menstrual hygiene practices among adolescent tribal girls in rural Gujarat, India. Reprod Health Matters. 2013;21(41):205-13.

9. Singh S, Kandpal SD, Roy D. Menstrual hygiene practices and RTI among ever-married women in rural slum. Indian $\mathrm{J}$ Community Health. 2011;23(1):41-3.

10. Arora A, Mittal A, Pathania D, Singh J, Mehta C, Bunger R. Impact of health education on knowledge and practices about menstruation among adolescent school girls of rural part of district Ambala,
Haryanam. Indian $\mathrm{J}$ Community Health. 2013;25(4):492-7.

11. Wickramasinghe D. Managing menstrual hygiene in emergency situations: how far from reality? ASIA Regional Sanitation and Hygiene Practitioners Workshop. Dhaka, Bangladesh, 31 January - 2 February 2012. Available at: http://www.wsscc.org/sites/default/files/publications/ wickramasinghe_menstrualhygiene-emergienciessrilanka_2012.pdf

12. Rani PS. Knowledge and practices of menstrual hygiene among married adolescents and young women in Chittoor District of Andhra Pradesh: India. IOSR J Nurs Health Sci. 2014;3(2):6-15.

13. Roy D. Epidemiology of reproductive tract infection in rural Wardha. In: Roy D, eds. A Thesis. Nagpur: Thesis submitted to Nagpur University for Doctor of Medicine; 1999.

14. Sakhi. HLFPPT. Hindustan latex family planning promotion trust, India, 2011. Available at: http://www.hlfppt.org/images/sakhi.pdf. Accessed 18 August 2011.

15. Dhingra R, Kumar A, Kaur M. Knowledge and practices related to menstruation among Tribal (Gujjar) adolescent girls. Ethno-Med. 2009;3(1):438.

16. Adinma ED, Adinma JI. Perceptions and practices on menstruation among Nigerian secondary school girls. Afr J Reprod Health. 2008;12(1):74-83.

17. Nemade D, Anjenaya S, Gujjar R. Impact of health education on knowledge and practices about menstruation among adolescent school girls of Kalamboli, Navi Mumbai. Health Popul Persp Issues. 2009;32(4):167-75.

18. Juyal R, Kandpal SD, Semwal J, Negi KS. Practices of menstrual hygiene among adolescent girls in a district of Uttarakhand. Indian J Community Med. 2012;24(2):124-8.

19. Dongre A, Deshmukh PR, Garg, BS. The effect of community-based health education intervention on management of menstrual hygiene among rural Indian adolescent girls. World Health Popul. 2007;9(3):48-54.

20. Karthikeyan GB, Sangeetha R. Women's attitude towards perception and derived satisfaction towards branded sanitary napkin, 2013. Available at: http://www.indianmba.com/Faculty_Column/FC153 7/fc1537.html. and http://www.indianmba.com/Faculty_Column/Faculty Column16/faculty_column16.html. Accessed 20 June 2014.

21. Poureslami M, Osati F. Attitude of female adolescents about dysmenorrhea and menstrual hygiene in Tehran suburbs. Arch Iran Med. 2002;5:377-96.

22. Barua A, Kathleen K. Reproductive health seeking by married adolescent girls in Maharashtra, India. Reprod Health Matters. 2001;9(17):53-62.

23. Seidman Y. Effects of a premenstrual syndrome education program on premenstrual 
symptomatology. Health Care Women Int. 1990;11(4):491-501.

24. Joshi D, Fawcett BN. Water, Hindu mythology and an unequal social order in India. Paper presented at the second conference of the International Water History Association, Bergen, Norway, 10-12, 2001. Accessed http://www.wateraid.org/ /media/publications/waterhindu-mythology-unequal-social-order.pdf.

25. Udgiri R, Angadi MM, Patil S. Knowledge and practices regarding menstruation among adolescent girls in an urban slum, Bijapur. J Indian Med Assoc. 2010;108:514-6.

26. Esimai OA, Esan GO. Awareness of menstrual abnormality amongst college students in urban area of Ile-Ife, Osun State, Nigeria. Indian J Community Med. 2010;35:63-6.

27. Singh MM, Devi R, Gupta SS. Awareness and health seeking behaviour of rural adolescent and reproductive health issues. Indian $\mathrm{J}$ Med Sci. 1999;53:439-43.

28. Omidvar S, Begum K. Menstrual pattern among unmarried women from south India. J Nat Sc Biol Med. 2011;2:174-9.

DOI: 10.5455/2320-1770.ijrcog20150203

Cite this article as: Reshmi RS, Gupta MK, Kumar D, Visengrawala F. An intervention to empower and engage the self-help groups for menstrual hygiene in Karnataka, India. Int J Reprod Contracept Obstet Gynecol 2015;4:15-22. 